\title{
RESERVATION FOOD SHARING AMONG THE ACHE OF PARAGUAY
}

\author{
Michael Gurven, Wesley Allen-Arave, Kim Hill, \\ and A. Magdalena Hurtado \\ University of New Mexico
}

\begin{abstract}
We describe food transfer patterns among Ache Indians living on a permanent reservation. The social atmosphere at the reservation is characterized by a larger group size, a more predictable diet, and more privacy than the Ache typically experience in the forest while on temporary foraging treks. Although sharing patterns vary by resource type and package size, much of the food available at the reservation is given to members of just a few other families. We find significant positive correlations between amounts transferred among pairs of families, a measure of the "contingency" component required of reciprocal altruism models. These preferred sharing partners are usually close kin. We explore implications of these results in light of predictions from current sharing models.
\end{abstract}

KEY WORDS: Cooperation; Food sharing; Hunter-gatherers; Reciprocity

Hunter-gatherer food sharing is often described as the band-wide pooling of unpredictable game resources and the more restricted pooling of gathered foods. One of the most detailed examples of this pattern was found among the Ache, a group of foragers living in eastern Paraguay (Hill and Hawkes 1983; Clastres 1972). Kaplan and Hill (1985) found that hunted game, such as peccaries, pacas, monkeys, and armadillos, was shared widely among all band members ( 15 to 28 people) who were on temporary forest trips away from the permanent Chupa Pou settlement. These foods

Received April 26, 2001; accepted July 2, 2001.

Address all correspondence to Michael Gurven, Department of Anthropology, University of California-Santa Barbara, Santa Barbara, CA 93106-3210. E-mail: gurven@anth. ucsb.edu

Copyright 2001 by Walter de Gruyter, Inc., New York

Human Nature, Vol. 12, No. 4, pp. 273-297.

$1045-6767 / 01 / \$ 1.00+.10$ 
were distributed so widely that wives and children of good hunters were no more likely to receive shares than were other individuals in the band. The unconditional band-wide nature of meat pooling was supported by the lack of any relationship between amounts produced and amounts consumed during forest trips, while the number of dependent offspring was the most significant predictor of amounts received. Kaplan and Hill (1985) argued that the Ache food-sharing pattern in the forest was best understood as an effective means of reducing the variance in daily food intake by buffering daily shortfalls with the receipt of food obtained from other hunters.

The Ache continue to spend up to a third of their time in the forest on daily or extended treks, living the rest of the time in swidden horticulture-based permanent settlements (or reservations). This study investigates Ache food-sharing behavior on the reservation, where cultivated foods constitute the bulk of the diet and where the vagaries of "luck" have little effect on total production. In an attempt to standardize the ways in which sharing is conceptualized and subsequently quantified, we introduce four measures of food transfers-depth, breadth, equality, and balance. Depth is defined as the percentage of food production given to others outside the nuclear family, and breadth is the number of nuclear families that receive shares per distribution or over some given time period. Equality reflects the disparities in amounts given to other individuals in the population during specific distributions, or over a significant time period, and balance refers to long-term similarities or differences in amounts transferred among specific pairs of nuclear families. These four measures can be used to study different aspects of sharing, and to help us distinguish between alternative models of food sharing.

Three models commonly invoked to explain cooperative behavior from an evolutionary perspective are reciprocal altruism (Rothstein and Pierroti 1988; Trivers 1971), tolerated theft (Blurton Jones 1987; Hawkes 1993; Winterhalder 1996), and costly signaling (Gurven et al. 2000b; Smith and Bliege Bird 2000). Reciprocal altruism is invoked when individuals or families preferentially share with those who share with them, whereas tolerated theft describes food flows from "haves" to "have-nots" when the costs of trying to defend extra food outweigh the benefits of hoarding. Thus, tolerated theft describes the pattern of egalitarianism and demand sharing depicted in many hunter-gatherer ethnographies (see Gurven et al. 2000a and Winterhalder 1997 for recent applications of these and other models to food sharing). Costly signaling occurs when display sharing is an honest signal of production ability, generosity, or another aspect of phenotypic quality. If the information value of the signal is valuable, then receivers of the signal may actively choose honest signalers as partners, al- 
lies, or mates; they are chosen not as a form of payback for food given (cf. trade-based reciprocal altruism) but because the costly sharing signal provides receivers with reliable information about the signaler that enables them to make more informed decisions about partner choice consistent with their own self-interest.

All three models predict outcomes that can result in the reduction of daily intake variance. Distinguishing between outcomes of all three models within a given ecological context has proven difficult (Bliege Bird and Bird 1997; Gurven et al. 2000a; Hill and Kaplan 1993). Reciprocal altruism and costly signaling provide benefits to those who share food, whereas tolerated theft provides none. Furthermore, only reciprocal altruism requires some form of contingency, or giving that is conditional on past or future receiving. Costly signaling allows return benefits to come from those who observe the signal or even those who hear about the signal. Tolerated theft assumes that food is given to others based on relative need and thus yields no return benefits to the donor.

In comparison to the foraging context, the reservation context is characterized by larger group size, higher dependence on more stable and predictable resources (less dependence on high-risk game resources), ${ }^{1}$ higher variation in work effort across individuals, and increased specialization among men. Although tolerated theft predicts smaller shares as group size increases and less widespread sharing as daily acquisition variance is reduced, it makes no specific predictions about changes in sharing breadth. Reciprocal altruism predicts that increased group size should restrict sharing behavior to small, interactive subsets (Boyd 1988) and that giving and receiving should become more positively correlated (Hill and Kaplan 1993; Gurven et al. 2000a). If reciprocal altruism is linked to risk-reduction benefits, we should also find that high-variance foods are shared with greater depth than low-variance foods. Table 1 summarizes the predictions made by reciprocal altruism, tolerated theft, and costly signaling with regard to sharing breadth, depth, equality, and balance. While specific predictions cannot always be made for each model (e.g., no model predicts exactly how much to give to first cousins), a certain range of observations would often be inconsistent with several models. Furthermore, some models are completely silent about expectations for several sharing measures (e.g., costly signaling on equality and depth), and thus any result would be consistent with those models.

The extent to which each of these models is relevant to the Ache in particular, or to foragers and forager-horticulturalists in general, is relevant to our understanding of several important aspects of human social behavior and life history. First, a sexual division of labor, where marriage between men and women is a cooperative enterprise geared towards raising 
Table 1. Predictions of Four Characteristics of Food Sharing According to Three Models of Food Sharing

\begin{tabular}{|c|c|c|c|c|}
\hline & \multirow[b]{2}{*}{ Sharing Feature } & \multicolumn{3}{|c|}{ Predictions Consistent with Each Model } \\
\hline & & $\begin{array}{c}\text { Tolerated } \\
\text { Theft }\end{array}$ & $\begin{array}{l}\text { Reciprocal } \\
\text { Altruism }\end{array}$ & Costly Signaling \\
\hline 1. & DEPTH & & $\begin{array}{l}\text { higher for un- } \\
\text { predictable, } \\
\text { asynchronously } \\
\text { acquired foods }\end{array}$ & $\begin{array}{l}\text { higher for } \\
\text { difficult-to- } \\
\text { acquire foods }\end{array}$ \\
\hline & $\begin{array}{l}\% \text { food given outside } \\
\text { family }\end{array}$ & $1-1 / N=96 \%$ & & \\
\hline 2. & BREADTH & & & \\
\hline & $\begin{array}{l}\text { a. } n \text { of family recipi- } \\
\text { ents per distribution }\end{array}$ & $\begin{array}{l}n \text { of hungry } \\
\text { families }\end{array}$ & $<N$ of families & $\leq N$ of families \\
\hline & $\begin{array}{l}\text { b. } n \text { of family recipi- } \\
\text { ents over sample }\end{array}$ & all families & $<N$ of families & $\leq N$ of families \\
\hline 3. & $\begin{array}{l}\text { EQUALITY } \\
\text { bias in amounts } \\
\text { received among } \\
\text { recipients }\end{array}$ & $\begin{array}{l}\text { no bias to in- } \\
\text { dividuals (kin, } \\
\text { friends, etc.) }\end{array}$ & ns & ns \\
\hline 4. & $\begin{array}{l}\text { BALANCE } \\
\text { differences in } \\
\text { production exchanged } \\
\text { between pairs of } \\
\text { families }\end{array}$ & $\begin{array}{l}\text { no contingency } \\
\text { between giving } \\
\text { and receiving }\end{array}$ & $\begin{array}{l}\text { contingency } \\
\text { between giving } \\
\text { and receiving }\end{array}$ & $\begin{array}{l}\text { does not require } \\
\text { contingency } \\
\text { between giving } \\
\text { and receiving }\end{array}$ \\
\hline
\end{tabular}

$N$ (number of nuclear families present) $=22$ at Arroyo Bandera

ns = no specific prediction can be made; any result would be consistent with the model.

offspring, requires coordination in men's and women's foraging goals (Bird 1999). If tolerated theft or costly signaling accounts for much of men's sharing, then traditional notions of marriage, hunting, the evolution of the nuclear family, and the role of male parental investment need serious revision (Bird 1999; Hawkes 1993). Second, our evolved human life history would have required substantial food transfers among group members across generations, and within generations, among families with varying needs (Kaplan and Gurven n.d.). Third, recent work by psychologists and economists attesting to prosocial cooperative behavior in humans (Hoffman et al. 1998), and an evolved psychology geared towards detecting cheaters (Cosmides and Tooby 1992) as well as altruists (Andrews in press), implicitly assumes a long exposure to some form of reciprocal altruism during the ancestral history of our species. 


\section{ETHNOGRAPHIC BACKGROUND}

The Ache of eastern Paraguay were full-time hunter-gatherers occupying a $20,000 \mathrm{~km}^{2}$ area between the Paraguay and Parana rivers until the time of contact in the mid-1970s. Many aspects of Ache socioecology, including foraging behavior, time allocation, food sharing, reproductive strategies, and life history have been well studied over the past 20 years (Hill and Hawkes 1983; Hill and Hurtado 1996; Hurtado et al. 1985; Kaplan and Hill 1985). One study has also focused on differences in time allocation and subsistence behavior between the mobile foraging and sedentary reservation contexts (Hawkes et al. 1987).

In terms of calories the Ache diet in the forest consisted of $78 \%$ wild game (mainly armadillo, capuchin monkey, agouti paca, and white-lipped peccary), $9 \%$ honey, and $12 \%$ collected goods (mainly palm fiber, palm heart, palm larvae, and oranges) (Kaplan et al. 2000). Preliminary analysis of weight data collected among the Ache at Arroyo Bandera (see below) indicates that during the sample period at the reservation the diet consisted of $80 \%$ cultigens (mainly sweet manioc, rice, peanuts, maize, and beans), $9 \%$ store-bought foods (mainly sugar, pasta, flour, yerba tea, and bread), $4 \%$ domesticated meat (pigs, chickens, and cows), and only $7 \%$ forest meat and other forest products (mainly armadillo, agouti paca, oranges, and honey). Although forest meat is a relatively small part of the current reservation diet, the Ache still place high value on meat acquisition, often complaining of "meat hunger" despite the availability of abundant (carbohydrate) calories at the reservation.

The Arroyo Bandera reservation was formed in 1980 when a group of Ache left the Chupa Pou settlement to live on the edge of a Guarani Indian reservation administered by a Protestant mission (Hill and Tikuarangi 1998). It is located on the western border of the Mbaracayu Reserve, to which the Ache have been given exclusive access for subsistence purposes. During the study period from January to May 1998 (wet- and early dryseason months) 117 permanent residents ( 34 adult men 16 years of age and older, 25 adult women age 16 and older, 24 boys, and 34 girls) were living in 23 nuclear family-based households in the community. The houses were small, wooden-board structures (constructed within the past two years), situated in a circular fashion around the perimeter of a small soccer field. The average distance between any two households was about $108 \mathrm{~m}$, with about half of all households ( $45 \%$ ) being in sight of each household.

\section{METHODS}

Data on complete food distributions ( $n=380$; mass $=1,030 \mathrm{~kg}$ ) were collected using a combination of randomized time blocks $(78 \%$ of all 
distributions), focal resource follows (10\%), and interviews (12\%). A time block is a 3-hour observation period (either 7-10 A.M., 10-1 P.M., 1-4 P.M., or 4-7 P.M.) of all food production, consumption, and distribution that occurred within a random cluster of households and thus constitutes a random sampling of food distributions and resources. The 150 time blocks divided among 8 household clusters resulted in 51-60 observation hours per household. Resource follows and interviews were conducted to obtain sharing data on less common resources unlikely to be observed during the time blocks, such as forest foods brought back to the reservation and large domesticated animals such as cows and pigs. Incomplete distributions ( $n$ $=635$, mass $=1,247 \mathrm{~kg}$ ), for which only a partial list of the recipients of a single food item was recorded, were not used in distribution analyses because of downward biases in estimates of the percentage of the resource kept within the nuclear family and the number of recipients. ${ }^{2}$

For each resource distribution that was observed from beginning to end, we recorded the identities of the donor, the acquirer, and all recipients, and estimates of total resource package size and amounts given to each recipient. Amounts were either weighed using $10 \mathrm{~kg}$ and $25 \mathrm{~kg}$ Homs spring scales or counted (as in sticks of manioc) and then converted to kilograms using unit weight measurements of counted resources. Furthermore, we subdivided events into source and subsequent distributions of raw or cooked foods. Source distributions $(n=228)$ detail the original distribution of a resource, where the acquirer and the donor are members of the same nuclear family. Subsequent distributions $(n=152)$ are any distributions where the acquirer and donor are members of different nuclear families. If Pedro from family 1 kills a $4 \mathrm{~kg}$ armadillo and his wife, Emilia, gives $2 \mathrm{~kg}$ to Carlos from family 2, who then gives half to Juanita from family 3 , the transfer from family 1 to family 2 is coded as a source distribution, while the transfer from family 2 to family 3 is coded as a subsequent distribution. There is considerable, although not complete, overlap between subsequent distributions and the distribution of cooked foods. In fact, the best estimate of percentage given to other nuclear families is the product of the percentage given away during source distributions of raw foods and the percentage given away during source distributions of cooked foods.

All analyses were done at the level of the nuclear family, so that family A gives to family B if any member of A gives to any member of B. We define nuclear family as married adults, their dependent offspring, and any older related members living in the same household. The household composition of Ache families varied substantially in 1998, as indicated by the wide range in ratio of consumers to producers (mean $=1.21$, range $=0$ to 3). To estimate kinship between nuclear families we coded the closest biological kinship relation between members of the two families. Residential proximity is the distance in meters between household residences. Visibil- 
ity was also measured because the orientation of households and the degree to which individuals must walk through the village to get to each other's houses varied across households. Nuclear families were scored as having very high, high, average, low, or zero visibility from any other household (coded from 4 to 0 , respectively), depending on the relative ease with which Gurven and Allen-Arave could observe the entrances, cooking, and eating areas from the other households in the community.

\section{RESULTS}

There were on average 5.6 source and 2.6 subsequent distributions per household per sample day. We explore the extent of sharing by examining sharing depth, breadth, equality, and balance.

\section{Depth}

Table 2 presents the sharing depth, or percentage of acquired food that was given to other nuclear families via source and subsequent distributions, for all food resources, by resource type (cultigens, domesticated animals, forest animals, other forest foods, and store-bought items) and package size. Village-wide distributions to all nuclear families consistent with a strict version of tolerated theft would result to close to $96 \%$ [1 $(22 / 23)$ nuclear families $\times 100$ ] being given away, yet few resources were redistributed this intensively. Resources that come in larger package sizes were characterized by greater sharing depth. Across resource categories,

Table 2. Sharing Depth and Breadth by Resource Type and Package Size

\begin{tabular}{|c|c|c|c|c|c|c|c|c|}
\hline \multirow[b]{2}{*}{ Category } & \multicolumn{4}{|c|}{ Source Distributions } & \multicolumn{4}{|c|}{ Subsequent Distributions } \\
\hline & $\mathrm{n}$ & $\begin{array}{c}\text { weight } \\
(\mathrm{kg})\end{array}$ & $\begin{array}{l}\% \text { given } \\
\text { to other } \\
\text { families }\end{array}$ & $\begin{array}{l}\mathrm{n} \text { of } \\
\text { recipient } \\
\text { families }\end{array}$ & $\mathbf{n}$ & $\begin{array}{c}\text { weight } \\
(\mathrm{kg})\end{array}$ & $\begin{array}{l}\% \text { given } \\
\text { to other } \\
\text { families }\end{array}$ & $\begin{array}{l}\mathrm{n} \text { of } \\
\text { recipient } \\
\text { families }\end{array}$ \\
\hline All food & 228 & 865 & 64 & 2.1 & 152 & 328 & 36 & 1.6 \\
\hline $\begin{array}{l}\text { Resource Type } \\
\text { cultivated }\end{array}$ & 132 & 375 & 52 & 1.6 & 89 & 188 & 48 & 1.2 \\
\hline domestic meat & 21 & 254 & 77 & 4.3 & 17 & 44 & 23 & 2.4 \\
\hline forest meat & 34 & 165 & 75 & 3.0 & 22 & 68 & 25 & 2.4 \\
\hline forest other & 9 & 21 & 76 & 3.0 & 7 & 10 & 24 & 1.9 \\
\hline $\begin{array}{l}\text { store-bought } \\
\text { Package Size }\end{array}$ & 41 & 51 & 45 & 1.7 & 16 & 18 & 55 & 1.8 \\
\hline$<4 \mathrm{~kg}$ & 171 & 211 & 41 & 1.5 & 130 & 176 & 59 & 1.4 \\
\hline $4-8 \mathrm{~kg}$ & 40 & 220 & 60 & 3.1 & 18 & 105 & 40 & 3.0 \\
\hline$>8 \mathrm{~kg}$ & 17 & 436 & 77 & 6.7 & 4 & 47 & 23 & 3.3 \\
\hline
\end{tabular}


percentages given away were directly related to the mean package size for those categories, although this relationship was not statistically significant: $1.3 \mathrm{~kg}$, store-bought; $2.3 \mathrm{~kg}$, other forest foods; $3.0 \mathrm{~kg}$, cultivated; 4.9 $\mathrm{kg}$, forest meat; $12.1 \mathrm{~kg}$, domesticated meat $(r=0.56, p=0.32, \mathrm{df}=4)$. However, although Figure 1 shows that package size differences account for much of the variance in sharing depth across resource types, differences between resource types remain (see below).

The extent to which Ache families share food is considerable. We can estimate the total percentage of food acquired that is consumed within the acquirer's nuclear family by multiplying the amounts kept within the family for source distributions of raw and cooked foods (not shown in Table 2). ${ }^{3}$ This gives us an estimate of only $13 \%$ of all food, or $21 \%$ of cultigens, $25 \%$ of store-bought foods, $9 \%$ of domesticated meat, $10 \%$ of forest meat, and $9 \%$ of other forest foods that were consumed within the nuclear family.

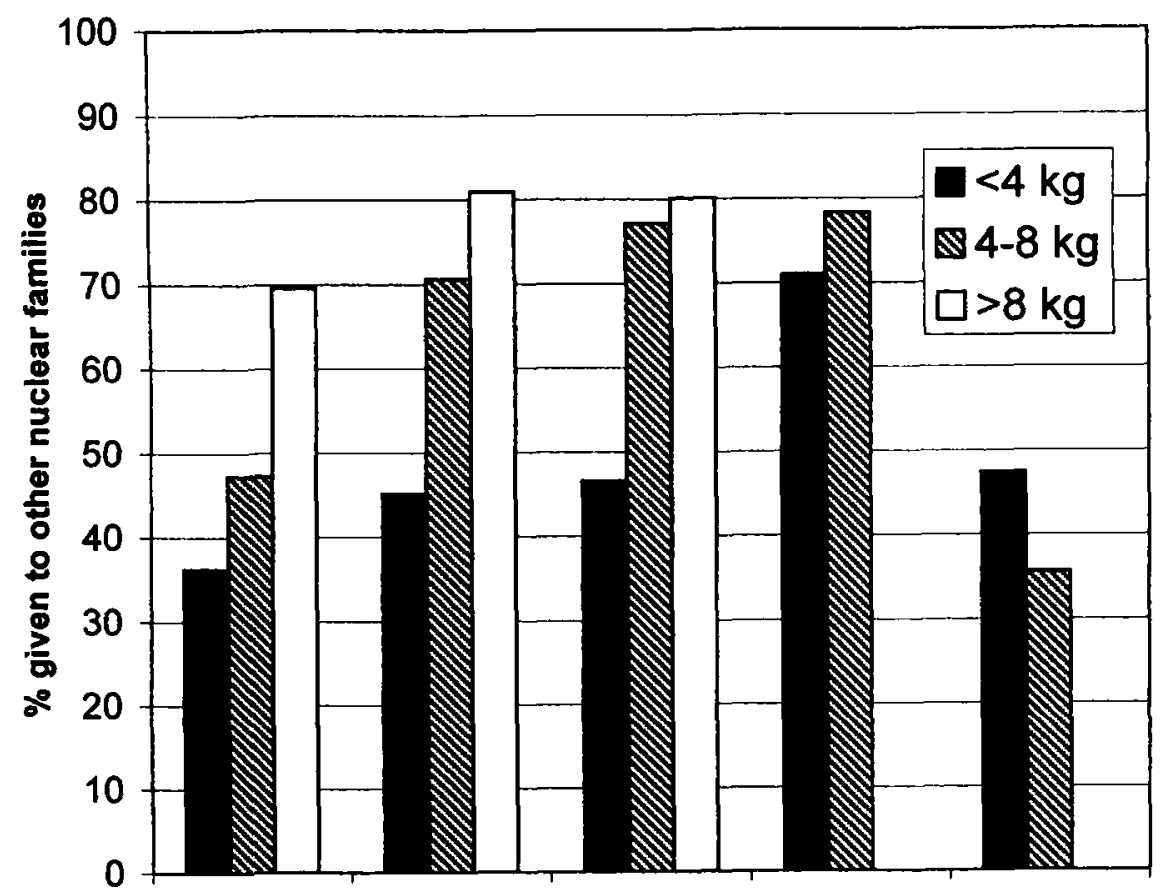

cultivated domest meat forest meat forest other storebought

Figure 1. Percent of food kept within the nuclear family by resource type and package size for source distributions. Resource types are cultigens, domestic meat, forest meat, other forest products, and store-bought foods. Package size is grouped into three categories: $<4 \mathrm{~kg}, 4-8 \mathrm{~kg}$, and $>8 \mathrm{~kg}$. 


\section{Breadth}

Table 2 also gives the sharing breadth, or average number of nuclear family recipients per source and subsequent distribution, for all food, by resource category and package size. Strict tolerated theft predicts $23 \mathrm{nu}$ clear family recipients per distribution if all potential recipients have equal stores of food, yet the overall breadth of sharing was relatively small. On average, only about two other nuclear families received food from a single distribution, resulting in a maximum total estimate of 10 other nuclear families eating portions from the same resource ( 1 acquirer +2.8 source recipients of raw food +1.7 source recipients of cooked food $+2.8 \times 1.7$ subsequent recipients of cooked food). Large-package foods (greater than $8 \mathrm{~kg}$ ) were given to a greater number of other nuclear families within and across resource types (Figure 2). For the most part, only large domesticated

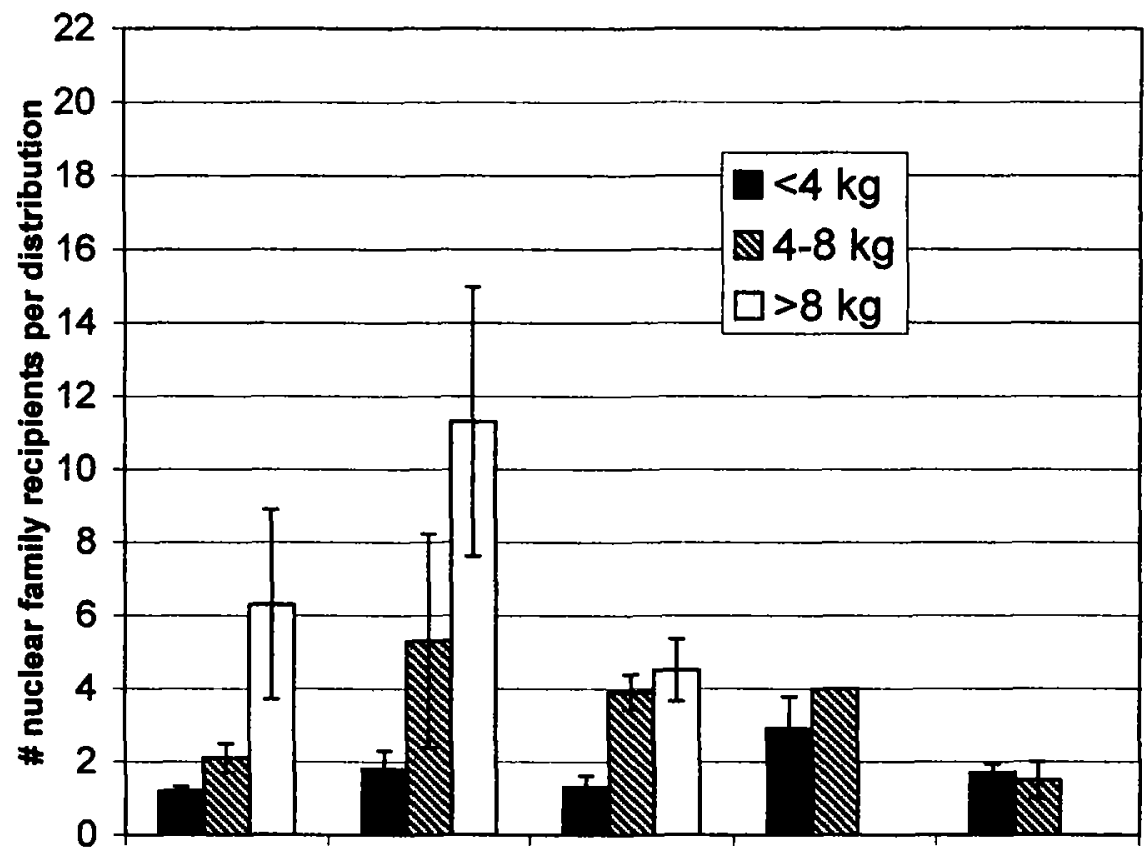

cultivated domest meat forest meat forest other storebought

Figure 2. Number of non-donor nuclear family recipients per distribution by resource type and package size for source distributions. Resource types are cultigens, domestic meat, forest meat, other forest products, and store-bought foods. Package size is grouped into three categories: $<4 \mathrm{~kg}, 4-8 \mathrm{~kg}$, and $>8 \mathrm{~kg}$. 
animals were distributed widely (almost the entire village received portions when subsequent shares were considered). However, these distributions were infrequent, occurring only once every 17 days in our sample, compared with the frequency of distribution of other food types (every 30 minutes for cultivated foods, 1.5 hours for store-bought, 1.8 hours for forest meat, 6.9 hours for other forest items).

Consistent with the tolerated theft-based prediction that high daily acquisition variance leads to widespread demands for shares is the finding that forest products were given to significantly more nuclear families than were cultigens (difference $=0.9$ families, partial $p<0.05$, controlling for package size), but still to far fewer than the potential number of families who lacked forest foods. A more accurate representation of tolerated theft is that when several individuals simultaneously acquire a certain valuable food, groups of recipients might cluster around each acquirer (an ideal free distribution: Fretwell and Lucas 1970), rather than all hungry recipients expecting to receive from all acquirers. Casual observation leads us to believe that daily variance in meat acquisition is much greater than the daily variance found in cultigen production (see above). However, the mean number of nuclear family recipients observed during the distribution of forest meat items is significantly smaller than that predicted by this more relaxed form of tolerated theft. Analysis of 441 single-day foraging trips from 1995 to 1999 showed an average of only 2.4 meat items acquired and brought back by hunters to Arroyo Bandera per day when someone hunts (s.d. = 2.03). Therefore, dividing the total potential number of nuclear family recipients by the number of nuclear families who acquired meat on any given day, we predict a minimal breadth of $23 / 2.4=9.6$ nuclear families per meat distribution. Table 2 shows that only 3.0 and 2.4 nuclear families received forest meat in source and subsequent distributions, respectively (maximum estimate $3.0+2.4+3.0 \times 2.4=12.6$ nuclear family consumers).

While the average number of other nuclear families that received shares in a given distribution was small, it is possible that the composition of nuclear families that received food from a given nuclear family varied across distributions. This could make the total number of nuclear family recipients (or donors) over time much larger than suggested by only examining means per distribution. In fact, the average number of nuclear families that received anything from a focal nuclear family over the entire sample period was only 12.0 (s.d. $=5.0$ ) and ranged from 2 to 22 . This means that an average nuclear family gave at least one share of food to $52 \%$ of all nuclear families in Arroyo Bandera (and none to $48 \%$ of all nuclear families) over the four-month sample period.

Even though nuclear families on average gave some food to half the village, most food sharing occurred with fewer than seven other nuclear families. Figure 3 gives the average percentage of a nuclear family's food 


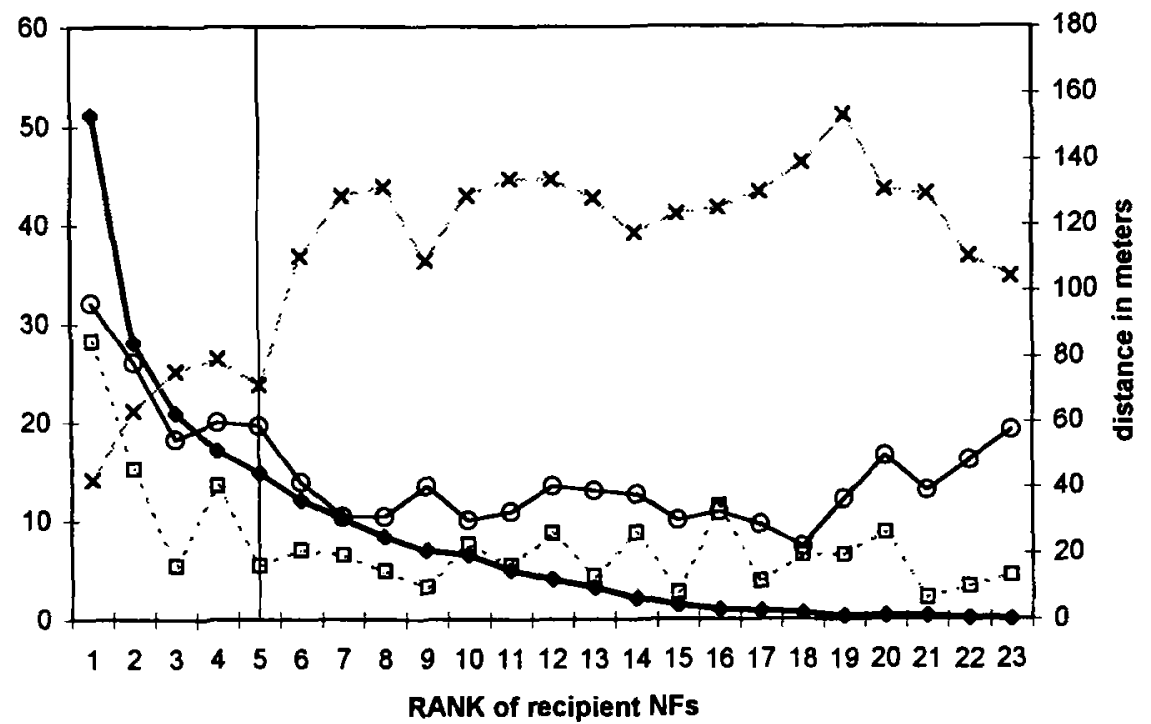

\begin{tabular}{|l}
$\cdots$ - avg $r$, coefficent of relatedness ${ }^{*} 100$ \\
- avg $\%$ of distributions where rank received a share \\
$\cdots \quad$ avg visibility ${ }^{*} 10$ \\
$\cdots \cdots$ avg distance, meters
\end{tabular}

Figure 3. Percent of all distributions of a focal nuclear family where each other nuclear family was a recipient, averaged across ranks from highest to lowest percent. For these ranks, the mean biological coefficient of relatedness $(r)$, residential proximity, and visibility between focal and recipient nuclear families are given.

distributions to each other nuclear family that received shares, with recipent families ranked from highest to lowest in terms of the percentage of distributions received during the sample period. The top-ranked recipient family on average received a share of more than half of a focal donor family's distributions. In fact, the top five recipient nuclear families received on average $75 \%$ of a donor nuclear family's total redistribution. This result, where many receive little to nothing, is inconsistent with a strict version of tolerated theft, which predicts the bold curve in Figure 3 to be flat, rather than steeply sloped downward.

\section{Equality}

Kinship, proximity, and visibility. A nuclear family has, on average, a close kin tie (at the 0.5 level: sibling, parent, or adult offspring) with 2.3 other nuclear families (range 0 to 7), a kin tie at the 0.25 level (niece/nephew and 
aunt/uncle) with 1.6 nuclear families (range 0 to 4), a kin tie at the 0.125 level (cousins) with 1.4 nuclear families (range 0 to 2 ), and no kin tie with 17.8 nuclear families (range 0 to 22). For both source and subsequent distributions, closely related kin (coefficient of relatedness, $r=0.5$ ) received more per distribution than distant kin and unrelated nuclear families (Figure 4; estimate $=2.8$ for source, 5.2 for subsequent, $p<0.0001$ ).

Residential proximity may correlate with amounts received if nuclear families are more willing to give food to neighbors, if neighbors are more likely to observe food consumption events and subsequently demand shares, or if close residential proximity reflects a preexisting desire to share. Table 3 shows that a visible and geographically close nuclear family received on average more food per source and subsequent distribution. In terms of overall proportions of food produced over the entire sample period, families in all visibility classes received food (there are many more nuclear families of low visibility than high visibility), while $76 \%$ of all food

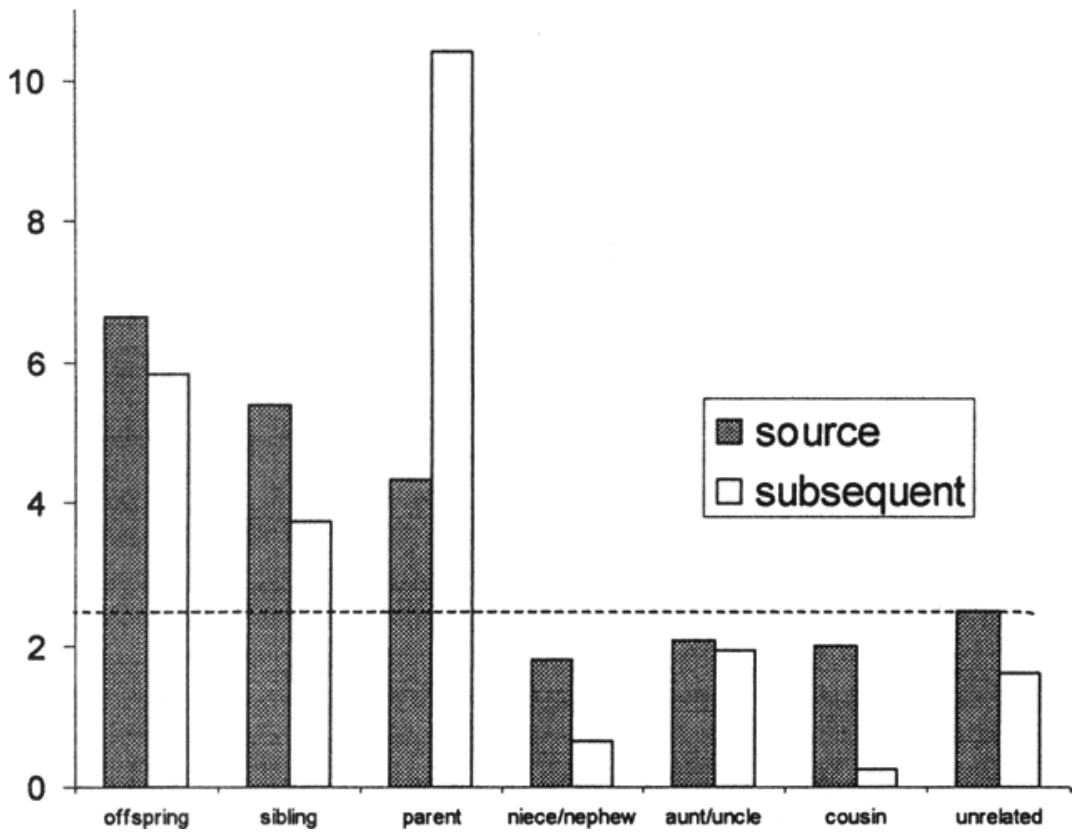

Relationship to Acquirer

Figure 4. Average percent of a resource item an individual receives per distribution by relatedness of recipient to the acquirer for source and subsequent distributions. 
Table 3. Percentage of a Resource Each Nuclear Family Received by Residential Visibility and Proximity

\begin{tabular}{|c|c|c|c|c|}
\hline \multirow[b]{2}{*}{ Proximity Measure } & \multicolumn{2}{|c|}{ Source Distributions } & \multicolumn{2}{|c|}{ Subsequent Distributions } \\
\hline & $\begin{array}{l}\text { \% family } \\
\text { received per } \\
\text { distribution }\end{array}$ & $\begin{array}{c}\% \text { all } \\
\text { food given } \\
\text { to class }\end{array}$ & $\begin{array}{l}\% \text { family } \\
\text { received per } \\
\text { distribution }\end{array}$ & $\begin{array}{c}\% \text { all } \\
\text { food given } \\
\text { to class }\end{array}$ \\
\hline \multicolumn{5}{|l|}{ Visibility between families } \\
\hline very high & 8.0 & 10.7 & 7.3 & 11.1 \\
\hline high & 4.0 & 8.0 & 2.9 & 5.6 \\
\hline average & 3.4 & 14.5 & 2.6 & 12.6 \\
\hline low & 2.1 & 7.9 & 0.9 & 3.4 \\
\hline none & 1.9 & 18.4 & 1.1 & 10.4 \\
\hline \multicolumn{5}{|l|}{ Distance between families } \\
\hline $0 \mathrm{~m}$ (within family) & 38.6 & 40.8 & 54.9 & 58.6 \\
\hline $1-25 \mathrm{~m}$ & 7.2 & 6.6 & 8.5 & 6.6 \\
\hline $26-50 \mathrm{~m}$ & 4.7 & 11.0 & 4.5 & 12.5 \\
\hline $51-75 \mathrm{~m}$ & 3.5 & 10.5 & 2.9 & 9.5 \\
\hline $76-100 \mathrm{~m}$ & 2.0 & 7.5 & 1.1 & 4.1 \\
\hline $101-125 \mathrm{~m}$ & 1.6 & 4.9 & 0.2 & 0.6 \\
\hline $126-150 \mathrm{~m}$ & 1.8 & 5.4 & 1.5 & 4.8 \\
\hline $151-175 \mathrm{~m}$ & 2.0 & 5.8 & 0.6 & 1.6 \\
\hline $176-200 \mathrm{~m}$ & 1.0 & 1.7 & 0.3 & 0.5 \\
\hline $201-225 \mathrm{~m}$ & 4.7 & 4.5 & 0.8 & 0.8 \\
\hline$\geq 226$ & 2.6 & 1.3 & 0.7 & 0.3 \\
\hline
\end{tabular}

in source distributions and $91 \%$ of all food in subsequent distributions were shared within a distance of $100 \mathrm{~m}$ of the donor household.

Although kinship and proximity may have independent effects on amounts received (see below), the direction of causality is ambiguous when the two are highly correlated; for example, some individuals may have chosen, in part, to live in close proximity to their kin for the purpose of preferential food sharing (Gurven et al. 2000a). In fact, close kin are not randomly dispersed in Arroyo Bandera. Pairs of nuclear families among the three kin categories in which $r=0.5$ (offspring, sibling, parent) that received more than the average (Figure 4 ) were on average $16 \mathrm{~m}$ closer ( $p<$ $0.05)$ and had an average visibility score 0.5 higher $(p<0.05)$ than found among pairs of nuclear families in other relatedness categories. More importantly, highly ranked recipient nuclear families were significantly closer in proximity (and more visible), and more closely related, to focal nuclear families than were lower ranked recipient nuclear families (Figure 3). These patterns are most profound for the top five ranked nuclear families, who together received from roughly $75 \%$ of all distributions.

We argue that these proximity effects are not necessarily the cause of sharing, as would be predicted by tolerated theft. While proximity is an 
important predictor of sharing depth and breadth, higher overall visibility and lower overall distance (as measured by the summed visibility scores and distance measures between a household and every other household) are uncorrelated with the percentage each nuclear family gave away over the entire sample period $(r=0.30, p=0.17, \mathrm{df}=21 ; r=0.10, p=0.66, \mathrm{df}=$ 21 ), the percentage each nuclear family gave away per event $(r=0.00, p=$ $0.15, \mathrm{df}=368 ; r=0.00, p=0.93, \mathrm{df}=362)$, and the total number of nuclear family recipients over the sample period $(r=0.00, p=0.84, \mathrm{df}=21 ; r=0.28$, $p=0.20, \mathrm{df}=21$ ). Thus, more visible households and households located in dense clusters do not give away more food or to more nuclear families than less visible and more geographically isolated households.

\section{Balance}

In-kind contingency. Contingency describes giving that is conditional upon past receipt and/or expected future receiving. We measure contingency between nuclear families $A$ and $B$ for resource type $Y$ as the percent total production of type $Y$ by nuclear family $A$ that is given to nuclear family $B$ for every one percent total production of $Y$ by nuclear family $B$ that is given to nuclear family $A$, over the entire sample period. Resource type $Y$ refers to all food, forest food, cultigens, or store-bought food. Contingency estimates for these resource types are given in Table 4 . We also report estimates where nuclear families are closely $(r=0.5)$ or distantly $(r<0.5)$ related, since reciprocal altruism theory was originally proposed to explain cooperative behavior among non-kin (Trivers 1971). The overall contingency estimate of 0.36 for all foods is a strong indicator that giving and receiving are correlated, even without considering the exchange of other non-food goods and services. Table 4 indicates that while contingency is positive and strong for store-bought and cultivated foods, it is weakest for forest foods. Moreover, contingency is significantly higher for closely related nuclear families than for distantly related and unrelated nuclear families across all resource types! This is consistent with the view that much of what was assumed to be kin-selected behavior in humans may actually be reciprocal altruism (see below).

Not-in-kind contingency (trade). Because some Ache make frequent forest treks whereas others concentrate on agricultural fieldwork or wage labor, we consider that trade across food types is likely. Thus, the best predictor of forest food given by A to B might be the amount of cultigens or storebought foods given by $B$ to $A$. Using multiple linear regression analysis, we find that cultigens received is the best predictor for cultigens given, and likewise for store-bought foods (bold estimates in lower portion of Table 4). Cultigens and store-bought foods received appear to be as useful 
Table 4. Contingency (\% family A gave to family B vs. $\%$ family B gave to family A)

\begin{tabular}{|c|c|c|c|c|c|c|c|}
\hline \multirow{6}{*}{$\begin{array}{l}A \text { to } B \\
\text { all food } \\
\text { forest } \\
\text { cultivated } \\
\text { store-bought } \\
\text { forest }\end{array}$} & $B$ to $A$ & \multicolumn{2}{|c|}{$\begin{array}{l}(\mathrm{n}=276) \\
\text { ALL } \\
\text { estimate }\end{array}$} & \multicolumn{2}{|c|}{$\begin{array}{c}(\mathrm{n}=29) \\
\text { CLOSE KIN } \\
(\mathrm{r}=0.5) \text { estimate }\end{array}$} & \multicolumn{2}{|l|}{$\begin{array}{l}(\mathrm{n}=247) \\
\text { NON-KIN } \\
\text { estimate }\end{array}$} \\
\hline & all food & 0.36 & $* * *$ & 0.45 & $* *$ & 0.22 & $* * *$ \\
\hline & forest & 0.10 & * & 0.16 & & 0.05 & \\
\hline & cultivated & 0.34 & $* * *$ & 0.63 & $* * *$ & 0.13 & * \\
\hline & store-bought & 0.41 & $* * *$ & 0.59 & $* * *$ & 0.08 & \\
\hline & forest & 0.07 & $\wedge$ & 0.10 & & 0.04 & \\
\hline & cultivated & 0.10 & $\wedge$ & -0.01 & & 0.11 & \\
\hline & store-bought & 0.10 & $*$ & 0.13 & & 0.07 & \\
\hline & & $\left(R^{2}=0.04\right)$ & & $\left(\mathrm{R}^{2}=0.09\right)$ & & $\left(R^{2}=0.01\right)$ & \\
\hline cultivated & forest & 0.07 & $\wedge$ & 0.01 & & 0.07 & \\
\hline & cultivated & 0.24 & $* * *$ & 0.46 & $* *$ & 0.11 & $\wedge$ \\
\hline & store-bought & 0.18 & $* * *$ & 0.16 & $*$ & 0.07 & \\
\hline & & $\left(R^{2}=0.17\right)$ & & $\left(\mathrm{R}^{2}=0.44\right)$ & & $\left(R^{2}=0.03\right)$ & \\
\hline store-bought & forest & 0.11 & $*$ & 0.22 & & 0.05 & \\
\hline & cultivated & 0.27 & $* * *$ & 0.53 & * & 0.08 & \\
\hline & store-bought & $\left(R^{2}=\begin{array}{r}0.32 \\
0.22)\end{array}\right.$ & $* * *$ & $\begin{array}{r}0.36 \\
\left(R^{2}=0.42\right)\end{array}$ & $*$ & $\begin{array}{r}0.07 \\
\left(R^{2}=0.03\right)\end{array}$ & \\
\hline
\end{tabular}

Note: partial $p$-values are from multiple linear regressions (see text)

${ }^{* * *} p$-value $<0.0001,{ }^{* *} p$-value $<0.001,{ }^{*} p$-value $<0.05, \wedge p$-value $<0.10$

as forest foods for predicting amounts of forest foods given, although the magnitudes of these estimates are small. Contingency is higher among closely related pairs of nuclear families across all resource type combinations except for the combination of cultigens and forest foods. However, the relationship between these two variables is not statistically significant. We see no evidence for incipient specialization and trade of food types. Instead, the data suggest that perhaps the advantages of economies of scale in harvesting lead to some turn-taking in food acquisition of specific types (see discussion).

\section{Multivariate Analysis of Depth, Equality, and Balance}

What affects how much an individual gives to other nuclear families?

We model the percentage of a resource given to other nuclear families as a function of several important ecological variables, including the resource type, resource package size, whether the resource was raw or cooked at the time of distribution, the ratio of consumers to producers in the donor nuclear family, and the sex and age of the donor $(F=8.4, p<0.0001$, $\mathrm{df}=374$; Table 5). The net effect of combining these variables in a single multiple linear regression analysis is to reduce the separate effects of each variable 
Table 5. What Affects How Much Individuals Give to Other Nuclear Families?

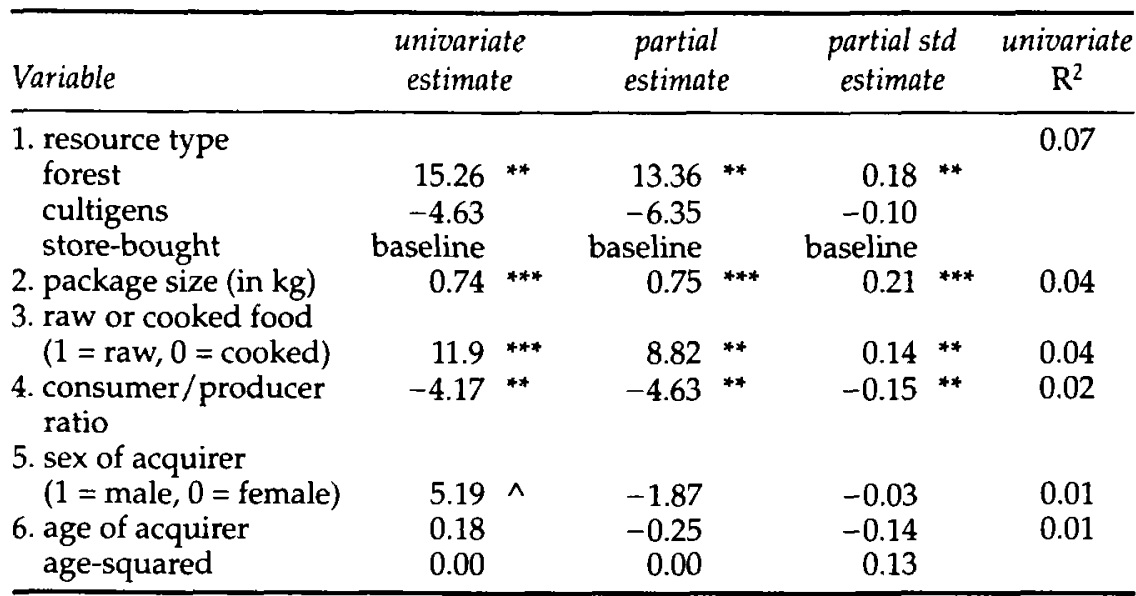

$F$-value $=8.4, p<0.0001 ; \mathrm{R}^{2}=0.15, \mathrm{df}=374$

${ }^{* * *} p$-value $<0.0001, * * p$-value $<0.001,{ }^{*} p$-value $<0.05, \wedge p$-value $<0.10$

Note: partial std estimates are standardized regression coefficients from the multiple regression where 1 standard deviation unit change in the predictor variable causes 1 standard deviation unit change in the outcome variable

on percent given. A difference between the univariate and partial estimate for a single variable indicates that one or more of the other variables in the model are confounding its effect on the outcome. Our analysis reveals that resource type has a significant effect on percentage given away, even after we control for resource package size. The results thus show that a higher percentage of forest products and a lower percentage of cultivated foods are given away than store-bought foods, which is consistent with the tolerated theft and reciprocal altruism condition where greater variance in acquisition leads to higher sharing depth (Table 1).

Furthermore, each additional kilogram in the package size of a resource is associated with an additional $0.75 \%$ given away, while an extra consumer in the farmily relative to the number of producers (consumer/producer ratio) is associated with about an additional $5 \%$ kept within the nuclear family. These results are consistent with all four models of sharing, and therefore reveal more about the general ecology of sharing than provide evidence to distinguish the relevance of the different models. Finally, both sex and age of the acquirer have little effect on sharing depth once we control for the other variables. ${ }^{4}$

What affects how much nuclear family A gives to nuclear family B?

A summary analysis of the percentage of total food production exchanged between all pairs of nuclear families reveals the relative effects of important socioecological variables. Table 6 summarizes multiple regres- 
Table 6. What Influences the Total \% of Nuclear Family A's Production Given to Nuclear Family B?

\begin{tabular}{lcccc}
\hline $\begin{array}{l}\text { Variable } \\
\text { \% B's total given to A } \\
\text { (range }=0-47 \%)\end{array}$ & $\begin{array}{c}\text { univariate } \\
\text { estimate }\end{array}$ & $\begin{array}{c}\text { partial } \\
\text { estimate }\end{array}$ & $\begin{array}{c}\text { partial std } \\
\text { estimate }\end{array}$ & $\begin{array}{c}\text { univariate } \\
\mathrm{R}^{2}\end{array}$ \\
$\begin{array}{c}\text { distance in meters from A to B } \\
\text { (range }=0-242 \mathrm{~m})\end{array}$ & $0.36^{* * *}$ & $0.27^{* * *}$ & $0.27^{* * *}$ & 0.15 \\
$\begin{array}{c}\text { visibility of B from A } \\
\quad(0=\text { lowest, } 4=\text { highest) }\end{array}$ & $-0.03^{* * *}$ & $-0.01^{* *}$ & $-0.15^{* *}$ & 0.11 \\
$\begin{array}{c}\text { closest kinship between A and B } \\
\text { (range }=0-0.5)\end{array}$ & $1.30^{* * *}$ & $0.52^{*}$ & $0.13^{*}$ & 0.10 \\
$\begin{array}{c}n \text { of individuals in B } \\
\text { (range }=2-9)\end{array}$ & $9.08^{* * *}$ & $5.21^{* * *}$ & $0.16^{* * *}$ & 0.07 \\
\hline
\end{tabular}

$F$-value $=25.5, p<0.0001 ; \mathrm{R}^{2}=0.26, \mathrm{df}=505$

${ }^{* * *} p$-value $<0.0001,{ }^{* *} p$-value $<0.001, * p$-value $<0.05$

sion analyses of the percent total of nuclear family A's food production given to nuclear family B on the percent total of nuclear family B's food production given to nuclear family $\mathrm{A}$ (contingency), geographical distance and perceived visibility between nuclear family $A$ and nuclear family $B$ (proximity), closest biological kinship between members of nuclear family $A$ and nuclear family $B$ (relatedness), and the number of non-producing dependents in nuclear family $B$ (need) $(F=25.5, p<0.0001, \mathrm{df}=505)$. The predictor with the largest standardized partial regression coefficient in the multivariate analysis of sharing between nuclear families is contingency. The partial estimates can be used to describe two extreme scenarios. A family that gave $50 \%$ of its total food production to a nearby (distance $=10$ $\mathrm{m}$ ), highly visible (visibility $=4$ ), closely related nuclear family (coefficient of relatedness, $r=0.5$ ) with 4 dependents can expect to receive $20 \%$ of that nuclear family's total food production in return, while a family that gave nothing to a distant $(150 \mathrm{~m})$, unrelated nuclear family $(r=0)$ of low visibility $(0)$ can expect to receive nothing from that nuclear family.

\section{DISCUSSION AND CONCLUSION}

We believe that the restricted sharing behavior observed among the Ache at Arroyo Bandera relative to that documented in the forest (Kaplan and Hill 1985) is more consistent with reciprocal altruism than strict tolerated theft or costly signaling. The Ache keep an average of $20-30 \%$ of what they acquire and give the rest to two or three other nuclear families, despite the fact that there were 22 other nuclear families who could potentially receive 
portions at any given time. There are also clear biases in distribution to close kin and reciprocal sharing partners. These results are inconsistent with tolerated theft, and with a simplistic version of costly signaling where sharing breadth is very high. Furthermore, the tolerated theft assumption that individuals do not own resources and therefore have little control over who receives food is not supported. Interview data collected to compare the number and identity of individuals who the donor said would receive shares prior to distribution with the number and identity of those who actually consumed shares revealed that Ache donors accounted for about $84 \%$ of the consumers (a difference of about 0.92 consumers, $n=26$ ). While much of the evidence presented in this paper is inconsistent with tolerated theft, we have not shown that this model or costly signaling are unimportant or irrelevant to Ache food sharing patterns. For example, the constant concern over not being labeled méllangi, or a stingy person, seems to motivate some individuals to share significant portions of their production. Consistent with costly signaling, it is possible that these individuals are either signaling generosity or high production ability (Gurven et al. 2000b), even if such production is given to only several other families. It is also possible that village-wide distributions of large domesticated animals such as horses and cows may be costly signaling or tolerated theft. Nonetheless, the most important result regarding typical daily sharing practices, inconsistent with tolerated theft (and indicative of reciprocal altruism), is the existence of contingency between giving and receiving among pairs of nuclear families.

We believe the importance of reciprocal altruism in empirical studies with traditional societies has been overlooked in recent years by researchers advocating kin selection and tolerated theft models. Studies of biological kinship and kin selection were pivotal in the growth of human sociobiology as a field. However, evidence in this paper suggests that while kin biases in various kinds of social behavior may be prevalent, we cannot assume that kin selection is the motivating force behind these biases. A comparison between Hamilton's rule for helping kin $(B / C>1 / r)$ (Hamilton 1964) and the rule derived by Axelrod and Hamilton (1981) for Tit-for-Tat-based cooperation (B/C >1/p), where $r$ is the coefficient of relatedness and $p$ is the probability of future interaction, indicates that whenever $p>r$, we can expect that reciprocal altruism will allow for helping behavior when kin selection does not. Thus, close kin are strong candidates for being reliable sharing partners since the probability of future interaction may be high, and the tendency to cheat might be low (Axelrod and Hamilton 1981). Although reverse causality is possible if kinship motivates closely related individuals to interact more, our evidence suggests that closest sharing partners (as measured by the top-ranked recipient nuclear families in Figure 3) are not strictly close kin (average $r$ of top three ranked recipient nuclear families $=0.28,0.15$, and 0.06 ). A future publica- 
tion will offer a more thorough treatment of reciprocal altruism and nepotistic kin selection, incorporating measures of $r, \mathrm{~B}$ and C. Nonetheless, it is apparent that the high level of food given to dependent offspring by parents and grandparents within nuclear families (where $B / C$ is likely to be large) is most likely driven by inclusive fitness benefits derived from kin selection.

The Ache are considered an egalitarian group, yet food does not consistently flow from the "haves" to the "have-nots." Instead, Ache sharing behavior at the reservation tends toward a pattern of small clusters of reciprocally sharing nuclear families. This pattern has been observed in two other settled groups for which quantitative food sharing data existamong the Yanomamö (Hames 2000) and the Hiwi of Venezuela (Gurven et al. 2000a). These three studies are the only ones to our knowledge that provide quantitative data necessary to detect reciprocal altruism in traditional societies. ${ }^{5}$ Furthermore, we believe that the restricted sharing observed among the Ache at the reservation can best be explained as a function of several key factors: group size, daily variance in work effort, riskiness and predictability of food resources, and economies of scale.

One explanation for the restricted sharing in Arroyo Bandera is that the marginal reduction in the probability of going without food on any given day becomes smaller with each additional member added to the sharing pool, even at relatively low group sizes (Winterhalder 1986), whereas levels of free-riding can expect to increase with group size (Boyd 1988). The overall level of variance in daily intake associated with manioc-based horticulture is low and does not demand large numbers of individuals to pool harvests, since daily consumption depends more on work effort than luck or random hazards (see below). Furthermore, as sharing group size increases, so does the temptation to free-ride off the efforts of others; thus, the costs of monitoring others to insure adequate returns increase with increasing group size. Both saturated benefits to risk-reduction and increased potential of free-riding support the restricted sharing networks found among nuclear families in Arroyo Bandera, as well as the relatively higher sharing breadth observed on foraging trips. A similar relationship between sharing breadth and group size has also been found among four Yanomamö groups (Hames 2000) and among the Yora of Peru (Hill and Kaplan 1989).

Another explanation for restricted sharing focuses attention on the existence and causality of variation in individual production. Whereas luck contributes significantly to daily variation in the quantities hunters produce, the amount of time spent clearing, burning, planting, weeding, and harvesting is probably the most important predictor of variation across nuclear families in cultigen production. In the forest context, there is relatively little daily variation in time spent hunting by Ache men (mean hours per day $=6.97$, s.d. $=2.40, n=1610$ ), and the number of hours each 
man spends hunting is not a statistically significant predictor of daily returns when day number is included in a multiple regression model (estimate $=-0.17, p=0.70, t=-0.39) .6$ This suggests that when factors beyond individual control dominate personal production, widespread pooling may be a beneficial and "fair" strategy, despite individual differences in skill and experience, whereas if personal work effort decisions dominate production returns, widespread pooling will be advantageous only for those who work little. Widespread pooling will be disadvantageous for those who are consistent hard workers, unless they are compensated with returns in another currency. Thus, when time investment and skill become critical determinants of food production, we might expect highly contingent food sharing.

From this perspective, we suspect that band-wide food sharing has often been misconstrued as "unconditional" giving (e.g., Sahlins's 1972 concept of generalized reciprocity). Instead, we suggest that pooling of food may be contingent on equality of work effort, or a form of "just desserts." For example: Tito gives Francisco food because Francisco was out hunting or doing some other work that could positively affect Tito. This is particularly relevant in ecologies where luck and spatiotemporal fluctuations in resource densities are important determinants of foraging success because total output (which will later be shared) can only increase with more total person-hours spent foraging. Although there are no examples of healthy Ache men refusing to hunt, the idea that sharing is contingent upon work effort is suggested by observations that individuals who refuse to participate in cooperative hunts are not invited to participate in future forest treks, and by reports that individuals must "hunt and attempt to kill something" in order to expect shares in band-wide meat distributions. Several anecdotal accounts among the Gunwinggu of Amhem Land (Altman 1987) and the Sirionó of Bolivia (Holmberg 1969) also support this argument. In both cases, individuals lax in their hunting tasks were either withheld shares or shared with to a lesser degree until they increased their productive efforts to expected levels. Further support for this hypothesis is found among the Hiwi of Venezuela. The Hiwi were hunter-gatherers whose diet consisted almost entirely of wild foods in the late 1980s, but who lived in a permanent settlement of about 120 people (Hurtado and Hill 1987). The largest determinant of their daily food production was time spent foraging because few individuals decided to forage on any given day. As expected, the observed food sharing pattern was very similar to that described here among the Ache in Arroyo Bandera (Gurven et al. 2000a).

A final important pattern observed in Ache settlement food sharing involves turn-taking in producing and sharing when there is an economy of scale (Kaplan et al. 1990). The fact that contingency is strong in the sharing of farm and gathered foods does not explain why such sharing might occur in the first place. The harvesting of cultigens such as manioc and 
corn may be examples of economies of scale if the costs of planting and harvesting additional amounts are small relative to the fixed costs of clearing fields and transporting harvests from the fields to the household. It then becomes efficient for an individual to (say) harvest $20 \mathrm{~kg}$ of manioc and share portions with other individuals who will later harvest manioc and return shares. Since sweet manioc generally cannot be stored for more than several days after harvesting, it would not be economically feasible for an individual to harvest large amounts without sharing. A reasonable strategy with an economy of scale is thus for groups of individuals to take turns harvesting large quantities of manioc and sharing food to other members within the group. Because turn-taking itself involves a form of reciprocity subject to free-riding, the total number of households that takes turns might be smaller than would be expected just from examining the economy of scale. The observed patterns of sharing both raw and cooked cultigens outside the nuclear family, allowing others to harvest cultigens from your fields, and the strong contingency-based sharing of cultigens all support this view. An economy of scale may also describe the contingent sharing of other foods, including palm fiber, oranges, and honey, during Ache foraging trips (Gurven et al. in press).

Large group size, increased daily variance in work effort, predictability of food resources, and the increased relevance of economies of scale when moving from forest to reservation contexts are complementary features of Ache socioecology that may interact to sustain high levels of food sharing. Assessing ways in which these features shape distribution patterns will require a detailed comparison between forest and settlement systems of food sharing and food production, and of differences in proximate circumstances that also affect the degree of food transfer (e.g., privacy, spatial proximity of individuals). This analysis will be the subject of a forthcoming paper (Gurven et al. in press).

This research was supported by an L.S.B. Leakey Foundation grant and an NSF Graduate Fellowship to M. Gurven, and NSF Grant \$9617692 to K. Hill and A. M. Hurtado. We thank the Ache at Arroyo Bandera for their generous hospitality, cooperation in our research, and of course, for their sharing food with us. Special thanks to Hillard Kaplan, who helped frame the scope and content of this paper, Garnett McMillan for his methodological insight and the use of his map of Arroyo Bandera, and to Rebecca Bird, Ray Hames, Eric Smith, and three anonymous reviewers for their useful comments on an earlier version of this paper.

Michael Gurven recently obtained his Ph.D. from the University of New Mexico and is now an assistant professor at UC-Santa Barbara. His current interests include exploring ways in which socioecology influences variation in cooperation within and across human groups, and how cultural norms of faimess co-evolve with systems of resource production and distribution.

Wesley Allen-Arave is pursuing his Ph.D. in anthropology at the University of New Mexico. His primary research interests focus on exploring variations across 
time and space in nonreciprocated altruistic acts, cooperation within social networks, and concerns over social approval.

Kim Hill is a professor of anthropology in the Human Evolutionary Ecology (HEE) program at the University of New Mexico. His primary research interests include hunter-gatherer behavioral ecology, life history theory, food acquisition strategies, food sharing, cooperation, and biodiversity conservation in lowland South America. He has done fieldwork with Nahautl, Ache, Guarani, Hiwi, Mashco Piro, Matsiguenga, and Yora indigenous peoples of Central and South America.

A. Magdalena Hurtado is associate professor of anthropology at the University of New Mexico. Her research interests include the evolution of cooperation between the sexes, infectious disease and immune system adaptations, the epidemiology of hunter-gatherer societies in transition, and the effects of health on economic productivity. During the past 20 years she has conducted fieldwork among several South American native populations but now works primarily among the Ache of eastern Paraguay.

\section{NOTES}

1. We define risk as unpredictable variation, so that high-risk refers to the relatively high probability that any single individual returns to camp empty-handed. The risk associated with foraging returns is usually modeled as the probability of falling below some critical threshold (Stephens 1990) and is usually equated with high variance in acquisition and (without sharing) consumption.

2. Most incomplete distributions were food transfers to a single nuclear family recipient.

3. For example, for all foods, $\%$ consumed within the family $=[100-75$ (avg $\%$ of raw foods given away in source distributions) $] \times[100-49$ (avg \% of cooked foods given away in source distributions)] $/ 100=13 \%$.

4. There was also no significant interaction effect between sex and age ( $p=$ 0.31) when sex*age was added to the multiple regression.

5. Bliege Bird and Bird (1997) show that there is no "general" contingency among Meriam hunters because those who give more turtle meat do not receive more turtle meat in return. Therefore, it is unlikely that hunters receive more from the specific hunters to whom they gave turtle meat. Sharing of this single resource therefore can be described as a sustained one-way flow. However, it remains to be seen whether recipients of turtle meat later return the favor in the form of other meat items, or other foods within the diet.

6. Data on men's hunting times were collected in 1980-1985 by K. Hill and $\mathrm{H}$. Kaplan. Data collected on time spent in daily food production at Arroyo Bandera have not yet been analyzed.

\section{REFERENCES}

Altman, J.

1987 Hunter-gatherers Today: An Aboriginal Economy of North Australia. Canberra: Australian Institute of Aboriginal Studies. 
Andrews, $P$.

in press Psychological Adaptation for Detecting Altruistic Displays: Accumulating Evidence from Wason Selection Task Studies. Cognition.

Axelrod, R., and W. D. Hamilton

1981 The Evolution of Cooperation. Science 211:1390-1396.

Bird, $R$.

1999 Cooperation and Conflict: The Behavioral Ecology of the Sexual Division of Labor. Evolutionary Anthropology 8:65-75.

Bliege Bird, R. L., and D. W. Bird

1997 Delayed Reciprocity and Tolerated Theft: The Behavioral Ecology of Food-sharing Strategies. Current Anthropology 38:49-77.

Blurton Jones, $\mathrm{N}$.

1987 Tolerated Theft: Suggestions about the Ecology and Evolution of Sharing, Hoarding, and Scrounging. Social Science Information 26:31-54.

Boyd, R.

1988 The Evolution of Reciprocity in Sizable Groups. Journal of Theoretical Biology 132:337-356.

Clastres, $P$.

1972 The Guayaki. In Hunters and Gatherers Today, M. Bicchieri, ed. Pp. 138-174.

New York: Holt, Rinehart, and Winston.

Cosmides, L., and J. Tooby

1992 Cognitive Adaptations for Social Exchange. In The Adapted Mind, J.

Barkow, L. Cosmides, and J. Tooby, eds. Pp. 163-228. New York: Oxford University Press.

Fretwell, S. D., and J. H. J. Lucas

1970 On Territorial Behaviour and Other Factors Influencing Habitat Distribution in Birds. Acta Biotheoretica 19:16-36.

Gurven, M., K. Hill, H. Kaplan, A. M. Hurtado, and R. Lyles

2000a Food Transfers among Hiwi Foragers of Venezuela: Tests of Reciprocity. Human Ecology 28:171-218.

Gurven, M., W. Allen-Arave, K. Hill, and A. M. Hurtado

$2000 \mathrm{~b}$ "It's a Wonderful Life": Signaling Generosity among the Ache of Paraguay. Evolution and Human Behavior 21:263-282.

Gurven, M., K. Hill, and H. Kaplan

in press From Forest to Reservation: Transitions in Food Sharing Behavior among the Ache of Paraguay. Journal of Anthropological Research 58(1), 2002.

Hames, R.

2000 Reciprocal Altruism in Yanomamo Food Exchange. In Human Behavior and Adaptation: An Anthropological Perspective, L. Cronk, N. Chagnon, and W. Irons, eds. Pp. 397-416. New York: Aldine de Gruyter.

Hamilton, W. D.

1964 The Genetical Evolution of Social Behavior. Journal of Theoretical Biology 7:1-52.

Hawkes, K.

1993 Why Hunter-gatherers Work: An Ancient Version of the Problem of Public Goods. Current Anthropology 34:341-361. 
Hawkes, K., H. Kaplan, K. Hill, and A. M. Hurtado

1987 Ache at the Settlement: Contrasts between Farming and Foraging. Human Ecology 15:133-161.

Hill, K., and K. Hawkes

1983 Neotropical Hunting among the Ache of Eastern Paraguay. In Adaptive

Responses of Native Amazonians, R. Hames and W. Vickers, eds. Pp. 139-188.

New York: Academic Press.

Hill, K., and A. M. Hurtado

1996 Ache Life History: The Demography and Ecology of a Foraging People. New York: Aldine de Gruyter.

Hill, K., and H. Kaplan

1989 Population Description and Dry Season Subsistence Patterns among the

Newly Contacted Yora (Yaminahua) of Manu National Park, Peru. National Geographic Research 3:317-324.

1993 On Why Male Foragers Hunt and Share Food. Current Anthropology 34: 701-710.

Hill, K., and T. Tikuarangi

1998 The Mbaracayu Reserve and the Ache of Paraguay. In Traditional Peoples and Biodiversity Conservation in Large Tropical Landscapes, K. H. Redford and J. A. Mansour, eds. Pp. 159-195. Arlington: America Verde.

Hoffman, E., K. McCabe, and V. Smith

1998 Behavioral Foundations of Reciprocity: Experimental Economics and Evolutionary Psychology. Economic Inquiry 36:335-352.

Holmberg, A. R.

1969 Nomads of the Long Bow: The Siriono of Eastern Bolivia. New York: Natural History Press.

Hurtado, A. M., and K. Hill

1987 Early Dry Season Subsistence Ecology of Cuiva (Hiwi) Foragers of Venezuela. Human Ecology 15:163-187.

Hurtado, A. M., K. Hawkes, K. Hill, and H. Kaplan

1985 Female Subsistence Strategies among Ache Hunter-gatherers of Eastern Paraguay. Human Ecology 13:1-28.

Kaplan, H., and M. Gurven

n.d. the Natural History of Human Food Sharing and Cooperation: a Review and a New Multi-individual Approach to the Negotiation of Norms. Ms. in preparation, Department of Anthropology, University of New Mexico.

Kaplan, H., and K. Hill

1985 Food Sharing among Ache Foragers: Tests of Explanatory Hypotheses. Current Anthropology 26:223-245.

Kaplan, H., K. Hill, K. Hawkes, and A. M. Hurtado

1984 Food Sharing among the Ache Hunter-gatherers of Eastern Paraguay. Current Anthropology 25:113-115.

Kaplan, H., K. Hill, and A. M. Hurtado

1990 Risk, Foraging, and Food Sharing among the Ache. In Risk and Uncertainty in Tribal and Peasant Economies, E. Cashdan, ed. Pp. 107-144. Boulder: Westview Press. 
Kaplan, H., K. Hill, J. Lancaster, and A. M. Hurtado

2000 A Theory of Human Life History Evolution: Diet, Intelligence, and Longevity. Evolutionary Anthropology 9:156-185.

Rothstein, S. I., and R. Pierroti

1988 Distinctions among Reciprocal Altruism, Kin Selection, and Cooperation and a Model for the Initial Evolution of Beneficent Behavior. Ethology and Sociobiology 9:189-209.

Sahlins, M.

1972 Stone Age Economics. Chicago: Aldine.

Smith, E. A., and R. Bliege Bird

2000 Costly Signaling and Turtle Hunting. Evolution and Human Behavior 21:245-261.

Stephens, D. W.

1990 Risk and Incomplete Information in Behavioral Ecology. In Risk and Uncertainty in Tribal and Peasant Economies, E. Cashdan, ed. Pp. 19-46. Boulder: Westview Press.

Trivers, R. L.

1971 The Evolution of Reciprocal Altruism. Quarterly Review of Biology 46: 35-57.

Winterhalder, B.

1986 Diet Choice, Risk, and Food Sharing in a Stochastic Environment. Journal of Anthropological Archaeology 5:369-392.

1996 A Marginal Model of Tolerated Theft. Ethology and Sociobiology 17:37-53.

1997 Social Foraging and the Behavioral Ecology of Intragroup Resource Transfers. Evolutionary Anthropology 5:46-57. 